\title{
Computational analysis of the inflow air slot size influence on solar vortex generator peformance
}

\author{
Ali A. Ismaeel ${ }^{1,2}$, Hussain H. Al-Kayiem ${ }^{1, *}$, Aklilu T. Baheta ${ }^{1}$ and Mohammed A. Aurybi ${ }^{1}$ \\ ${ }^{1}$ Solar Thermal Advanced Research Center, Universiti Teknologi PETRONAS, 32610 Bandar Seri \\ Iskandar, Perak, Malaysia. \\ ${ }^{2}$ Department of Electromechanical Engineering, University of Technology, Baghdad, Iraq
}

\begin{abstract}
Nowadays, attention is directed towards the possibilities of harnessing the potential of tornado by creating an artificial convective vortices for green electricity generation. In view of this research trending, a novel new solar vortex power generator, designed, fabricated and experimented at University Technology PETRONAS, Malaysia. In this paper, ANSYS - FLUENT 15 software was used to simulate the influence of inflow slot size on the vortex updraft velocity. Two cases hav been investigated. Case 1 with new dimension of $0.1 \mathrm{~m}$ width and guide vane height of $0.6 \mathrm{~m}$. Whereas, case 2 with slot dimension of $0.3 \mathrm{~m}$ height and $0.15 \mathrm{~m}$ width. From the attained results, it could be deduced that the slot size is an important parameter which impacts on the vortex strength. The vortex exit velocity increased by $50 \%$ a nd by $2.6 \%$ for the case 1 and case 2 , respectively. This indicates that the slot height is highly influencing the vortex strength. Thus far, the indexes from the numerical simulation can be used in re-designing of the inflow slot size for optimal performance.
\end{abstract}

\section{Introduction}

It is well-known that extreme weather phenomena's, such as dust devils, tornadoes, and waterspouts can cause tremendous collateral damage to a nation's infrastructure and inhabitant [1]. There have been several efforts put in place by different governments, academia and research scientist around the world towards utilizing, reducing or eliminating the negative impact of this veraciousness on the society. Many studies have made it known that vortices rotate in an updraft column of the air and a three-dimensional flow with high kinetic energy potential [2]. In view of the aforementioned theories, there are now attempts to produce green electric power sources by exploiting the potential of vortex energy application from renewable energy.

However, the mechanism of the method strictly rely on generating artificial updraft i.e. hot air like vortex, which converts thermal energy to a mechanical work because of the convective heat instituted during upward motion of air similarly to the mechanism of how heat engine or Rankine engine operates, $[3,4]$. In creating an artificial swirling, tornado-like air motion, two main variables are important: the rotation of the air and updraft movement of

*Corresponding author: hussain_kayiem@utp.edu.my 
the air [5]. A mechanical swirling device which air circulation is accomplished by getting the air tangentially in an internal heading, (interior winding ribbing, screws, vortex tube, guide twirl vanes and others) [6]. Similarly, an updraft vortex stream approach was build up [7], using a heat source to upgrade the buoyancy forces of the hot air. Likewise, a concept of solar vortex engine (SVE) was conceived in the study of [8]. In their design, a two-way component is designed; one aligned with the solar air collector (SAC) and the second vortex engine (VE). Herein, the vortex is created convectional by twisting and heating the incoming ambient air flow from the SAC using guide vanes. The integration of the vortex generator with the solar heat trap cavity (SHT) which enhances the stack effects thereby maintaining the vortex updraft continuously and the new model of vortex generator (VG) with double solar absorbing system known as solar vortex power generator (SVPG). In order to understand the vortex flow generated by VG, (2017), investigated the influence of inflow air parameters to $\mathrm{VG}$ in relation to temperature and velocity. The investigation of the influence of extended initial inflow slot and guide vane height between $0.3 \mathrm{~m}$ to $0.6 \mathrm{~m}$ for vortex updraft generation [9]. Despite several attempts presented by different researchers, yet, investigation on inflow slot design of VG is sparsely mentioned.

The present work, simulate computationally the effect of increase in the inflow slot width from $0.1 \mathrm{~m}$ to $0.15 \mathrm{~m}$ using computational fluid dynamics (CFD) by ANSYS fluent software version 15 to choose the best model that will be used in modify of VG for maximizes the SVPG performance.

\section{Description of the model}

The model of SVPG was designed, fabricated and experimented in Solar Thermal Advanced Research Center (STARC) at University Technology PETRONAS, Malaysia. The SVPG consist of three primary components. The first part is the solar collector (SC), which represents the greenhouse effects. Herein, the irradiation is converted to stream of air by series of energy conversion process. The ambient air is heated and circulates towards artificial vortex generator (AVG) in the second part. In the solar heat trap (SHT) unit which consist of both transparent upper cover (TUC) and transparent structure (TS), creates the initial convective vortex by absorbing the solar irradiance to heat up the air inside the AVG thereby creating updraft flow and simultaneously reducing the heat inside the SAC parts of the AVG. The airflow is accelerated inside the guide vane by creating inside the AVG a rotational swirling motion identical to vortex. An electrical generator was added in the path of the vortex-induced flow of the wind turbine to generate electricity, by extracting kinetic energy to produce power. However, the three cases simulated and discussed in this paper are described in table 1.

Table1: Description of the cases in terms of the heights and widths of the air entrance and guide vanes dimensions.

\begin{tabular}{|c|c|c|c|}
\hline Cases & Air entrance & Guide vane & Description \\
\hline Initial state & $\begin{array}{c}\text { width }=0.1 \mathrm{~m}, \\
\text { height }=0.3 \mathrm{~m}\end{array}$ & Height $0.3 \mathrm{~m}$, & Height $0.6 \mathrm{~m}$, \\
\hline Case 1 & $\begin{array}{c}\text { width }=0.1 \mathrm{~m}, \\
\text { height }=0.6 \mathrm{~m}\end{array}$ & $\begin{array}{c}\text { Extended the vanes and entry } \\
\text { slot height }\end{array}$ \\
\hline Case 2 & $\begin{array}{c}\text { width }=0.15 \mathrm{~m}, \\
\text { height }=0.3 \mathrm{~m}\end{array}$ & Height $0.3 \mathrm{~m}$, & $\begin{array}{c}\text { Extended the air entry slot } \\
\text { width }\end{array}$ \\
\hline
\end{tabular}

The design configuration for the SVPG are shown in Fig 1 with the dimensions of the AVG as follows: diameter of the inner cylinder $=0.9 \mathrm{~m}$, height of inner cylinder $=0.6 \mathrm{~m}$, diameter of outer cylinder $=1 \mathrm{~m}$, height of outer diameter $=0.6 \mathrm{~m}$, guide vanes angle $=25^{\circ}$, 
height of guide vane $=0.3 \mathrm{~m}$, length of guide vane $=0.35 \mathrm{~m}$, entry slot width and height $=$ $0.1 \mathrm{~m}$ and $0.3 \mathrm{~m}$, respectively. The transparent structure has a polygon shaped with $0.6 \mathrm{~m}$ in height, whilst the cover diameter is $0.1 \mathrm{~m}$ with $0.3 \mathrm{~m}$-diameter hole at the epicenter of the cover, used for the vortex updraft flow exit.

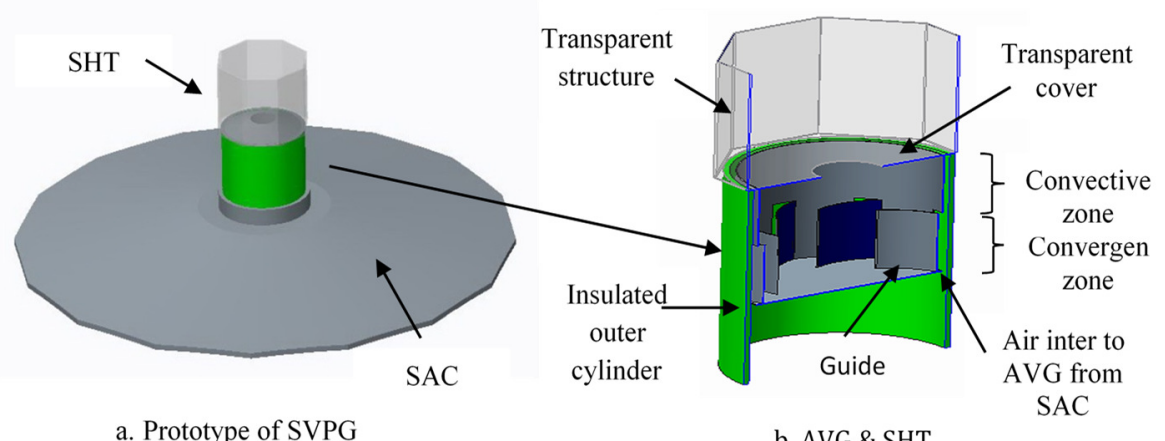

Fig. 1. Outlines of the SVPG model

\section{Numerical investigation}

\subsection{Numerical Simulation Methods}

Boussinesq model for natural convection was applied with Fluent simulation by Joe et al. 2002 [11]. In the model, density is assumed constant all through the equations except for the buoyancy term in the momentum equation. The k- $\varepsilon$ turbulence model and RNG simulation were performed. Whereas, the Semi Implicit Method for Pressure Linked Equation Consistent (SIMPLEC) algorithm was employed for the 2nd order discretization for pressure; momentum and energy obtain more converged solution. The irradiance load passing across the transparent Perspex which heats up the beneath air is represented by the radiation model using Discrete Ordinates (DO).

\subsection{Governing Equations}

The conservation of continuity equation, momentum and energy balance equations have been applied to study the flow field within AVG. The Equation 1. means no change in mass with time and when the density is constant. After assuming incompressible viscous flow, body force action in y direction only and steady state flow. the conservation of mass equation can be written as follows:

Continuity equation:

$$
\left(\frac{\partial u}{\partial x}+\frac{\partial v}{\partial y}+\frac{\partial w}{\partial z}\right)=0
$$

Momentum equation:

$$
\begin{aligned}
& \rho \nabla \cdot(u V)=-\frac{\partial p}{\partial x}+\frac{\partial \tau_{x x}}{\partial x}+\frac{\partial \tau_{y x}}{\partial y}+\frac{\partial \tau_{z x}}{\partial z}+S_{x} \\
& \rho \nabla \cdot(v V)=-\frac{\partial p}{\partial y}+\frac{\partial \tau_{x y}}{\partial x}+\frac{\partial \tau_{y y}}{\partial y}+\frac{\partial \tau_{z y}}{\partial z}+S_{y}
\end{aligned}
$$


Turbulence model:

$$
\rho \nabla \cdot(w V)=-\frac{\partial p}{\partial z}+\frac{\partial \tau_{x z}}{\partial x}+\frac{\partial \tau_{y z}}{\partial y}+\frac{\partial \tau_{z z}}{\partial z}+S_{z}
$$

$$
\begin{aligned}
& \rho \frac{\partial}{\partial x_{i}}\left(k u_{i}\right)=\frac{\partial}{\partial x_{j}}\left(\alpha_{k} \mu_{e f f} \frac{\partial k}{\partial x_{j}}\right)+G_{k}+G_{b}-\rho \varepsilon-Y_{M} \\
& \rho \frac{\partial}{\partial x_{i}}\left(\varepsilon u_{i}\right)=\frac{\partial}{\partial x_{j}}\left(\alpha_{\varepsilon} \mu_{e f f} \frac{\partial \varepsilon}{\partial x_{j}}\right)+G_{1 \varepsilon} \frac{\varepsilon}{k}\left(G_{k}+C_{3 \varepsilon} G_{b}\right)-C_{2 \varepsilon} \rho \frac{\varepsilon^{2}}{k}-R_{\varepsilon}
\end{aligned}
$$

Energy equation:

$$
\rho C_{p}\left(\frac{\partial(u T)}{\partial x}+\frac{\partial(v T)}{\partial y}+\frac{\partial(w T)}{\partial z}\right)=k\left(\frac{\partial^{2} T}{\partial x^{2}}+\frac{\partial^{2} T}{\partial y^{2}}+\frac{\partial^{2} T}{\partial z^{2}}\right)+S_{E}
$$

The radiation equation which is solved by the software can be written as:

$$
\nabla \cdot\left(I_{\lambda}(\vec{r}, \vec{s}) \vec{s}\right)+\left(a_{\lambda}+\sigma_{s}\right) I_{\lambda}(\vec{r}, \vec{s})=a_{\lambda} n^{2} I_{b \lambda}+\frac{\sigma_{s}}{4 \pi} \int_{0}^{4 \pi} I_{\lambda}(\vec{r}, \vec{s}) \varphi\left(\vec{s} . \vec{s}^{\prime}\right) d \Omega^{\prime}
$$

The solar intensity in each direction $\vec{S}$ and position $\vec{r}$ can be written as follows [12]:

$$
I_{\lambda}(\vec{r}, \vec{s})=\sum_{k} I_{\lambda}(\vec{r}, \vec{s}) \Delta \lambda_{k}
$$

$\vec{r}=$ position vector, $\vec{s}=$ direction vector, $\vec{s}=$ scattering direction vector, $\alpha=$ absorption coefficient, $n=$ refractive index, $\sigma_{s}=$ scattering coefficient, $\sigma=$ Stefan-Boltzmann constant $\left(5.669 \times 10^{-8} \mathrm{~W} / \mathrm{m}^{2} \cdot \mathrm{K}^{4}\right), I=$ radiation intensity, which depends on $\vec{r}$ And $\vec{s}, T=$ temperature, $\phi=$ face function, $\hat{\Omega}=$ solid angle, $\lambda=$ wave length, $\alpha_{\lambda}=$ spectral absorption coefficient, $I_{b \lambda}=$ black body intensity, $S_{\mathrm{h}}=$ Heat source due to incident solar radiation, $\mathrm{G}_{\mathrm{k}}=$ Production of turbulent kinetic energy, $\mathrm{G}_{\mathrm{b}}=$ Generation of turbulence kinetic energy due to buoyancy, $\mathrm{C}_{3 \varepsilon}=$ constant to calculate the degree of $\varepsilon$ effected by buoyancy.

\section{Result and discussion}

The influence of the inflow slot geometry on the solar vortex generator performance has been simulated by [10] in 2017 with slot size of $0.3 \mathrm{~m}$ height, $0.1 \mathrm{~m}$ width. [10] refersed that the vortex flow behavior within the AVG \& SHT for the initial geometry of inflow slot showd that air blocks happened in convection zone and formatted a small circulation motion like a convection current between the end of guide height and the transparent cover of the AVG. Also, the convection currents were appeared around the swirl flow in the SHT zone causes to split the vortex into two stream which weaken the stack effect that necessary to extend the vortex into atmosphere and that consider as a negative impact due to decrease the air fresh flow rate incoming into the system as shown in Figure 2. While, after the extended the convergence region height from $0.3 \mathrm{~m}$ to $0.60 \mathrm{~m}$ (case 1) is It is obvious there was no rotatory motion created inside the AVG after increase the vane guide and inflow slot height, due to prevent the air for assembly as an air block inside the generator. Therefore, all the air inflow from the slot into AVG was moved towards the upper hole with the high kinetic energy, in view of the rise in air flow rate to the turbine. In addition, the flow pattern of the vortex updraft was extended inside the SHT without any divergence whereas in the initial case there was none. The reason behind this phenomenon is the great kinetic energy generated after increase the convergence zone height, lead to increase both of the vertical and tangential velocity compound and as a result, allowed the vortex to overcome the convective current into the SHT as describe in Fig 3a 


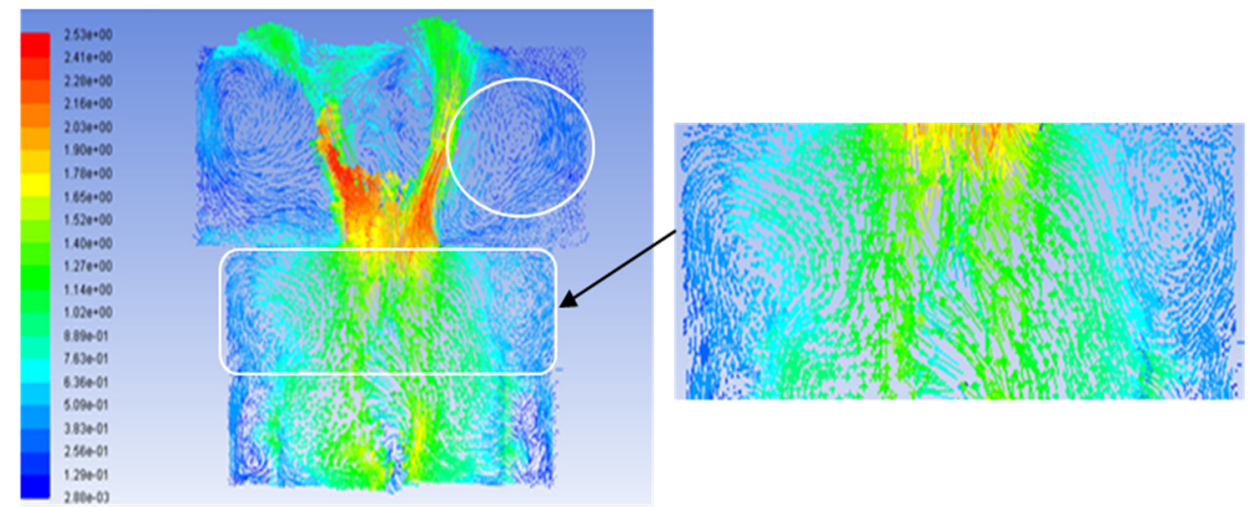

Fig. 2. Velocity distribution within AVG and SHT for the initial case

When the inflow slot width increased from $0.1 \mathrm{~m}$ to $0.15 \mathrm{~m} \mathrm{Fig.} 3 \mathrm{~b}$ shows the vortex flow behavior according to the case 2 slot size. The simulation shows, the direction of the swirling air flow as a similarity with the behavior flow in initial case ( without any change in the height and width). which, the divergence flow and the circulation motion is still occurring in the convective zone and inside the SHT unit. In addiation, the vorticity, velocity magnitude and energy generated is listed in Table 2.

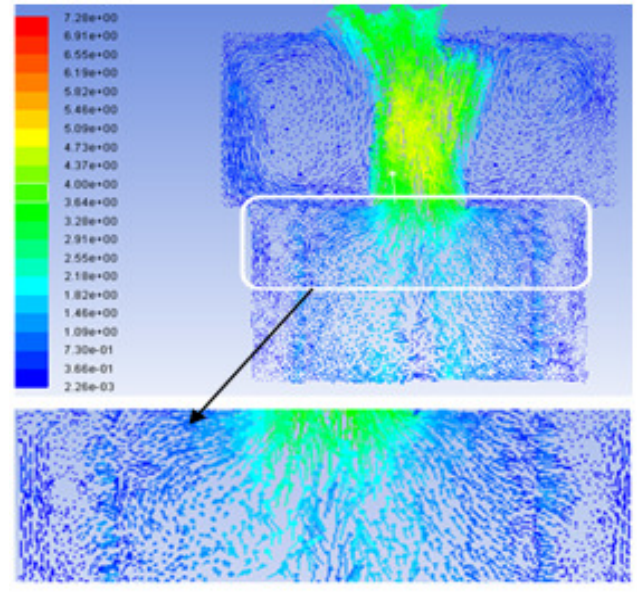

a. Velocity vector with inflow slot dimesion in case 1

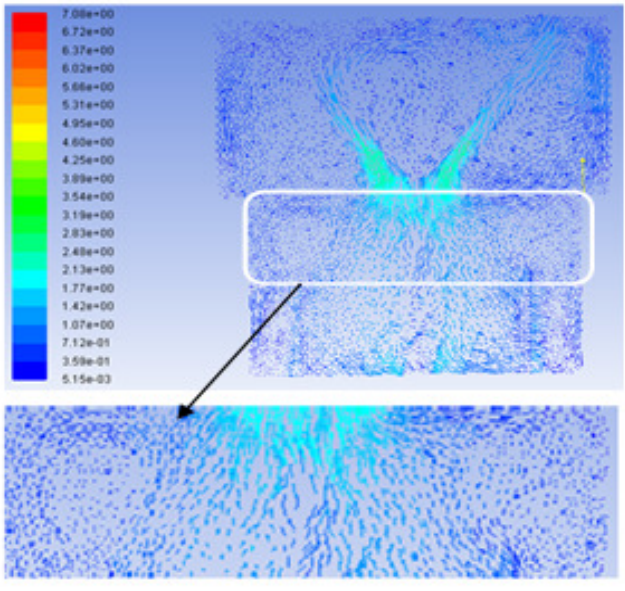

b. Velocity vector with inflow slot dimesion in case 2

Fig. 3. Velocity vector distribution within AVG and SHT after change the inflow slot geometry.

Table 2. Result of the vorticity, velocity magnitude and energy generated with different simulation of AVG design

\begin{tabular}{|c|c|c|c|}
\hline Cases & Vorticity $\left(\mathbf{s}^{\mathbf{- 1}}\right)$ & $\begin{array}{c}\text { Updraft velocity } \\
(\mathbf{~ m} / \mathbf{s})\end{array}$ & Energy (J) \\
\hline Initial state & 82 & 1.85 & 0.924 \\
\hline Case 1 & 123 & 3.7 & 2.77 \\
\hline Case 2 & 80 & 1.9 & 0.926 \\
\hline
\end{tabular}


From the table, it is clearly shown that the design AVG according to case 1 model give a higher vorticity and vortex energy. That is indicate that, increase the inflow slot area of the vortex generator by extend the slot width without extend the guide height is not effected on the vortex flow behavior, like when increase inflow slot and vane guide height.

\section{Conclusions}

Solar vortex air generator integrated with solar heat trap unit to mimick artifitial swirl updraft has been simulated and presented with a focus on the inflow slot size influence on the vortex flow structure. The results have been carried out for two cases and compared with a bench mark from previous work. The CFD results demonstrated that the slot size is role design parameter influencing the vortex strength. In addiation, the slot design of extended the air entrance and guide vane height is more efficient for enhance the velocity generated compared with the design of extended the air entrance width only. It is highly recommended to investigate a modified exit structure to avoid the flow circulation under and above the cover plate.

The authors wish to acknowledge the logistic supports given by the Universiti Teknologi PETRONAS and the financial support by Ministry of Higher Education (MOHE) Malaysia to produce and publish the current paper under FRGS/1/2017/STG02/UTP/03/2, CS: 0153AB-K81. In particular, the main author acknowledges University of Technology - Iraq for approving a study leave to llow him pursue his $\mathrm{PhD}$ study.

\section{References}

1. S. Nizetic, Transactions of Canadian society for mechanical engineering 38 (1), 81-91 (2014).

2. $\quad$ S. Nizetic, Energy 36 (2) , 1236-1242 (2011).

3. A.A. Ismaeel, H.H. Al-Kayiem, A.T. Baheta and M.A Aurybi, IET Renewable Power Generation 11(13), 1613-1624 (2017)

4. S. Nizetic, Journal of cleaner production 170, 85-95( 2018)

5. A. Varaksin, M.E. Romash and V.N. Kopeitsev, "Tornado-like vortex generation due to air turbulent convection". 14th European Turbulence Conference, France, 1-4 September, 2013.

6. A. Varaksin, M.E. Romash and V.N. Kopeitsev, International Journal of Heat and Transfer, 55(23-24), 6567-6572 (2012)

7. H.S. Takhar and O.A. Beg, International Journal of Fluid Mechanics Research, 32 (4), (2005).

8. A.T. Mustfa, PhD. Mechanical Engineering Department, Universiti Teknologi PETRONAS, Perak, Malaysia, 2016.

9. A.A. Ismaeel, H.H. Al-Kayiem, A.T. Baheta and M.A Aurybi, MATEC Web of Conferences 131, 02009 UTP-UMP SES, EDP Sciences (2017).

10. A.A. Ismaeel, H.H. Al-Kayiem, A.T. Baheta and M.A Aurybi, WIT Transactions on Ecology and the Environment 224, 553-563,WIT Press (2017).

11. H.F. Joe land P.E. Milovan, "Computational Methods for Fluid Dynamics", Third edition book Publications: Springer, 2002.

12. ANSYS Fluent Theory Guide (2013). 